\title{
PENGARUH ISLAM DALAM KEBUDAYAAN LOKAL DI BUTON: Satu Kajian Berdasarkan Teks Sarana Wolio
}

\author{
La Niampe \\ FKIP Universitas Haluoleo \\ Jl. H.E.A. Mokodompit, Kendari, Telp.081245779970 \\ email: niampe@yahoo.com
}

\begin{abstract}
This study aimed to describe how far the moslem teaching has given influence to the local culture in Wolio (Buton). This study researched a classic script text, therefore used a filology and Heuristic methode. filology methode was used to purify text and make text be readable by the citizen, whereas heuristic methode was used to find out the substantial of the text. The result of this study showed that Islamic teaching influenced toward local culture in Buton since Sultan Mobolina Pauna administration. When he arranged the constitution of Buton verbally called as "Martabat Tujuh "or Sarana Wolio is like influenced by his intuition or his sufism perspective. That influence could be seen through the culture which was arranged like Martabat Tujuh, determining of sultan's number and sapati which was symbolized by sifat dua puluh, determining of minister number was symbolized like thirty of juz alqur'an and determining number of points refused by culture were symbolized by "itikad yang tujuh puluh dua kaum"
\end{abstract}

Penelitian ini bertujuan untuk menguraikan sejauh mana ajaran Islam telah berpengaruh dalam kebudayaan lokal di Wolio (Buton). Oleh karena objek yang diteliti berupa teks naskah kuno, maka metode yang digunakan adalah metode Filologi dan metode Heuristik. Metode filologi digunakan untuk memurnikan teks serta mebuat teks menjadi terbaca oleh masyarakat umum, sedangkan metode Heuristik digunakan untuk menemukan substansi teks. Hasil penelitian menunjukkan bahwa ajaran Islam mulai berpengaruh terhadap budaya lokal di Buton sejak masa pemerintahan sultan Mobolina Pauna. Ketika beliau 
menyusun Undang-Undang Buton secara tertulis yang disebut "Martabat Tujuh" atau "Sarana Wolio", tampaknya sangat dipengaruhi perasaan atau alam pemikiran kesufiannya. Pengaruh itu terlihat pada produk adat yang disusunnya seperti penetapan pangkat-pangkat ditamsilkan dengan Martabat Tujuh, penetapan jumlah adat Sultan dan Sapati ditamsilkan dengan sifat dua puluh, penetapan jumlah mentri ditamsilkan dengan tiga puluh juz al Quran dan penetapan jumlah itikat yang ditolak oleh adat ditamsilkan dengan "itikad yang tujuh puluh dua kaum".

Key words: Moeslim, tasawuf, sarana wolio, culture

\section{Pendahuluan}

Berbicara tentang proses masuknya Islam di Buton tentu tidak dapat terlepas dari proses masuknya Islam di Asia Tenggara. Masuknya Islam di Asia Tenggara merupakan suatu proses yang progresif dan bermula dangan penukaran beberapa unsur penting di kalangan penduduk dari segi perundangan serta juris prudensi kurang lebih pada tahun 1200-1400 M, diikuti dengan pengenalan unsur-unsur falsafah pada tahun 1400-1700 M, serta diikuti dengan perkembangan bentuk pemikiran rasional-keagamaan. Hubungan antara Islam dan kebudayaan lokal tidak semestinya sesuatu yang progresif di sisi pandangan Islam, begitu juga ia tidak semestinya sesuatu yang sejajar (Hooker, 1991: 41).

Proses msuknya Islam di Buton dimulai pada tahun $984 \mathrm{H}$ atau tahun 1542 M (La Niampe, 2010: 499). Pada masa itu, raja yang memerintah di kerajaan Buton bernama La Kilaponto gelar Sultan Murhum. Meskipun Islam telah diterima di Buton sejak pertengahan abad ke-16, akan tetapi belum diketahui pengaruh ajarannya sepanjang paruh kedua abad ini (Yunus, 1995: 19). Yang diketahui barulah gelar sultan, nama penghormatan dari kata arab yang digunakan oleh raja. La Kilaponto adalah raja Buton yang pertama kali menggunakan gelar sultan. Gelar sultan yang digunakan ini merupakan pengaruh kultur Islam yang juga berlaku bagi kerajaan-kerajaan lain di Nusantara yang telah menerima Islam.

Pengaruh Islam yang lebih jauh terjadi nanti setelah kesultanan Buton memasuki abad ke-17. Sumber lokal menyebutkan bahwa pada masa pemerintahan La Elangi gelar Sultan Dayanu Ikhsanuddin atau Mobolina Pauna (1597-1631) meletakkan undang-undang kerajaan yang disebut dengan "Martabat Tujuh", disebut demikian karena berisi ajaran Martabat Tujuh, suatu ajaran yang dikenal dalam dunia tasawuf (Schoorl, 
2003: 139). Martabat Tujuh, berati tujuh peringkat atau tujuh kedudukan. Nama ini merujuk kepada ajaran mistik sufi yang pada awal abad ke-17 sangat berkembang pesat di Aceh (Braginsky, 1993: 21).

Tulisan ini mendeskripsikan sejauh mana ajaran Islam telah berpengaruh dalam kebudayaan lokal di Buton. Adapun sumber kajiannya adalah teks naskah "Sarana Wolio" yang dikarang oleh Sultan Muhammad Idrus Kaimuddin tahun $1243 \mathrm{H}$ atau $1827 \mathrm{M}$. Muhammad Idrus adalah sultan Buton ke-29 (1824-1851). Naskah ini tersimpan di koleksi Abdul Mulku Zahari di Buton dengan nomor kode koleksi 179 Wolio/19/91. Selain itu, naskah ini tersimpan pula di koleksi Arsip Nasional RI, Perpustakaan Nasional RI dan di KITLV Leiden Belanda, masing-masing dalam bentuk mikrofilm.

Naskah memiliki ukuran; 72 halaman $15-25$ baris/halaman, 32, 5x $10 \mathrm{~cm}$. Alas yang digunakan adalah kertas Eropa bercap Lion Medallion Concordia. Teks naskah ditulis dalam bahasa Wolio dengan menggunkan aksara Arab (Buri Wolio). Jenis tinta yang digunakan terdiri atas dua warna yaitu warna hitam dan merah. Status naskah diperkirakan asli, kondisi fisik naskah secara umum tidak begitu baik, kertasnya telah mengandung warna kekuning-kuningan (terdapat bercak-bercak cairan yang membentuk gumpalan). Kondisi kertas agak lapuk dan rapuh menunjukkan bahwa usia kertas telah tua, akan tetapi teks naskah masih lengkap dan masih dapat terbaca dengan jelas.

\section{Metode Penelitian}

Metode yang digunakan dalam penelitian ini adalah metode filologi, suatu metode yang menggunakan naskah kuno (manuskrip) sebagai dasar kajiannya. Secara sederhana, inti pekerjaan seorang filolog ialah membuat sebuah naskah menjadi bermanfaat bagi pembacanya. Dalam pada itu, penyajian dan interpretasi sebuah naskah sangat diperlukan (Rabson, 1994: 13). Filologi lahir dilatarbelakangi oleh sejumlah faktor yakni: (1) munculnya informasi tentang masa lampau di dalam sejumlah karya tulisan: (2) anggapan adanya nilai-nilai yang terkandung dalam peninggalan tulisan masa lampau yang dipandang masih relevan dengan kehidupan masa sekarang, (3) kondisi fisik dan substansi materi informasi akibat rentang waktu yang panjang, (4) faktor sosial budaya yang melatarbelakangi penciptaan karya-karya tulisan masa lampau yang tidak ada lagi atau tidak sama dengan latar sosial budaya pembaca masa kini, dan (5) keperluan untuk mendapatkan hasil pemahaman yang akurat (Baried dkk, 1994: 2). 
Untuk keperluan menganalisis teks, digunakan metode heuristik, yaitu pembacaan teks secara berulang-ulang sehingga menemukan subtansi daripada masalah teks itu secara utuh atau secara totalitas. Dalam menganalisis sebuah teks, harus memperlihatkan keistimewaannya sebagai keseluruhan yang koheren, harus memperlihatkan bagian-bagiannya yang saling bersangkutpaut, harus menunjukkan ciri khas struktur dan penggunaan bahasannya (Sutrisno, 1983: 91).

\section{Hasil dan Pembahasan}

\section{Adat Pertama di Tanah Wolio (Buton)}

Menurut Teks "Sarana Wolio" adat pertama di tanah Wolio meliputi empat hal pokok. Perhatikan terjemahan kutipan teks berikut:

"Ketahuilah olehmu, permulaan istiadat di tanah Wolio ini empat banyaknya; pertama-tama, saling menakuti; kedua, saling memelihara; ketiga, saling menyayangi; keempat, saling menghormati. yang melebihi kita, kita ta'dzimi, yang sama dengan kita, kita pelihara, yang di bawah kita, kita sayangi. Yang dihormati itu banyak; ada karena keberaniannya pada adat Wolio; ada karena kealimannya di jalan adat Wolio; ada karena mengorbankan hartanya pada adat Wolio; ada yang kita hormati itu karena membawa kepandaiannya di jalan pemerintah dalam menyelesaikan pekerjaan adat Wolio. Apa saja ada jalan saling menghormati selain yang telah tersebut itu. Adapun jumlah orang yang dihormati itu semua nama yang berjasa pada adat Wolio. Adapun penghormatan itu bermacam-macam; ada yang dihormati itu ucapan; /4/ada yang dihormati itu jabatan; ada yang dihormati itu harta; ada yang dihormati itu kelakuan. Itulah pengasah mata hati manusia di tanah Wolio ini, agar tidak luntur dan tidak tumpul, supaya tetap tajam, bahkan bertambah, hanya Allah yang tahu".

\section{Adat Buton Zaman Mobolina Pauna.}

Menurut teks "Sarana Wolio" bahwa pada zaman Mobolina Pauna mulailah diadakan; pangkat-pangkat (struktur jabatan adat), adat dua belas, adat delapan, adat lima dan adat sembilan. Perhatikan terjemahan kutipan teks berikut:

"Pada zaman Moßolina Pauna diadakanlah pangkat-pangkat; diadakanlah adat yang dua belas; diadakanlah adat yang delapan; diadakanlah adat yang lima; diadakanlah adat yang sembilan. Semua sara yang disebutkan itu ada batasan-batasan dan rahasiannya".

\section{Pangkat-Pangkat (Struktur Adat)}

Menurut teks Sarana Wolio, pangkat-pangkat berteladan pada "Martabat Tujuh" perhatikan terjemahan kutipan teks berikut: "Adapun pangkat-pangkat itu berteladan dari Martabat Tujuh. Pertama- 
tama yang disebut Martabat Tujuh itu martabat ahadiah. Yang disebut ahadiah itu zat Allah semata-mata, tidak i'tibar sifat, itulah yang disebut oleh ahli sufi la ta'yun, artinya tidak nyata kenyataannya sebab tidak ada sama sekali jalannya akal, yang diketahui semata-mata zat Allah itu, tidak muncul i'tibar sifat atau asma. Yang kedua Martabat Tujuh itu martabat wahdah. /5/ Yang disebut wahdah itu sifat Allah. Itulah yang disebut ahli sufi Ta yun awal, artinya kenyataan pertama. Disebut sebagai kenyataan pertama karena pertama-tama akal itu telah ada jalan untuk mengetahui zat Allah itu terlebih dahulu memahami sifat Allah, karena sifat itulah yang menunjukkan zat, baik sifat sulbi atau sifat maujud sebagaimana wujud kata zâtullâhi qadîmun, artinya zat Allah SWT itu sedia adanya atau zâtullâhi qadîmun artinya zat Allah SWT itu kekal atau zatullahi mukhâlifatu lilhawâditsi, artinya zat Allah itu berbeda dengan segala sesutau yang baru atau sebagaimana firmanNya zâtuhu yatusifu bilhiâti artinya zat Allah. Allah itu disifatkan dengan hidup dan segala simbolnya seumpama itu. Ketiga, martabat tujuh itu martabat wahidiyah. Yang disebut wahidiyah itu adalah asma Allah. Itulah yang dinamakan ahli sufi tayun tsâni, yang artinya kenyataan /6/ kedua. Dinamakan dengan kenyataan kedua karena juga dengan asma Allah itu dapat ditembus akal untuk mengetahui zat Allah, karena asma itulah yang menunjukkan zat yang bersifat segala sifat yang sesuai dengan zat-Nya sebagaimana firman Allah samî̀u bashîrun, artinya Allah SWT itulah Tuhan yang maha mendengar lagi maha melihat. Samîun bashir itulah dua asma yang menunjukkan zat yang bersifat samâ dan yang bersifat bashar. Martabat yang tiga inilah yang qadim baqâ. Yang mendahulukannya dan yang mengakhirkannya itu akal bukan zaman. Jika yang lebih dahulu zamannya, maka jika demikian maka lebih dahulu ada zat-Nya baru sifat-Nya lalu asma-Nya. Mustahil sekali Allah SWT demikian itu, karena Allahu itu zat-Nya, sifat-Nya dan asma-Nya itu adalah bersatu, qadim, baqâ, ketiganya itu, munculnya satu per satu itu supaya ditembus akal. Yang keempat Martabat Tujuh itu /7/ martabat alam arwah. Itulah keberadaannya semua nyawa, baik nyawanya manusia ataupun nyawa yang lainnya. Pertama-tama, ruh yang dijadikan Allah SWT itu ruh Nabi kita shalallahu alaihi wasallam. Itulah yang dinamakan abû al arwâh artinya bapak semua nyawa. Karena dia mendahului segala ruh yang lain. Nabi SAW bersabda; awwalu mâ halaqa Allâhu Tâla rûhiy. Artinya, pertama-tama yang dijadikan Allah SWT ruhku satu kati dan dua laksa dan empat ribu tahun lebih dahulu ruh Muhammad, kemudian ruh yang lainnya. Keberadaan yang lainnya itu karena kelebihan Nabi shalallahu alaihi wassalam. Firman Allah SWT di dalam hadits qudsi; khalaqtul asy yâ'a li ajalika wa khalaqtuka li ajali artinya, Aku buat satu-satu karena engkau dan aku, buat engkau karena aku dia itu, kemudian nyawa yang lainnya. Urutanurutan kejadiannya, yang lebih didahulukan dan yang kemudian dikemudiankan. Ruh itulah /8/ keadaan yang halus tidak dapat dibagi-bagi, tidak dapat dipilahpilah, tidak dapat disusun-susun, kehalusan nyawa itu karena terlampau amat kecil, dinamakan halus, ruh itu karena tidak dicapai panca indera yang lima yang lahir pada manusia itu seperti pendengaran telinga, atau penglihatan 
mata, atau penciuman hidung atau perasaan lidah atau persentuhan badan. Orang Arab menyebut nyawa itu ruh, karena nyawa itu keluar masuk. Jadi dalam bahasa Arab disebut ruh, dalam bahasa Wolio disebut lipa. Karena jika telah dikehendaki oleh Allah SWT menghidupkan jasad itu, maka diletakkanlah nyawa oleh Allah pada jasad itu. Jika Allah menghendakai agar jasad itu mati, maka dikeluarkanlah ruh dari jasad itu. Ruh itu tidak pernah mati. Setelah tiba di akhirat, ruh itu dikembalikan lagi pada jasad hanya saja bukan lagi seperti bentuknya yang ini, dia telah besar telah tinggi. /9/ Allahu SWT, yauma tubaddalul ardla ghairal ardli, artinya pada hari itulah nanti telah diubah tanah dengan tanah yang lainnya. Karena itu ahli sufi mengambil dalil ini sebab yang mengandungkan unsur yang empat, jasad itu tanah. Yang kelima, martabat tujuh itu martabat alam mitsal. Itulah contohnya semua keberadaan. Setelah keberadaan Allah SWT, tidak ada, artinya contohnya semua keberadaan. Setelah keberadaan, Allah SWT itu mengerjakan satu-satu Allah SWT lebih dahulu contoh-contohnya. Mustahil betul Allah SWT seperti itu walaupun alam mitsal itu contoh bagi semua keberadaan. Oleh karena keberadaan alam mitsal itu bermacam-macam rupa, hanya Allah SWT juga yang mengetahui banyaknya. Ada seperti nyawa, bukan nyawa, ada seperti badan bukan badan, ada seperti malaikat bukan malaikat, ada seperti /10/ jin bukan jin, ada seperti manusia bukan manusia, ada seperti batu bukan batu, ada seperti kayu bukan kayu, ada seperti binatang bukan binatang. Tidak ada yang tidak ada, semua keadaan arwah dan semua keberadaan ajsam yang tidak ada contohlnya di alam mitsal itu. Keberadaan alam mitsal itu akhir dari keberadaan alam arwah. Itulah juga keadaan halus, tidak dijangkau panca indera yang lima yang disebut pertama itu. Yang keenam, martabat tujuh itu martabat alam ajsam. Itulah semua keberadaan yang nyata ini seperti tanah, seperti bulan, seperti awan, seperti batu, seperti kayu, seperti air dan semua yang dinamakan keberadaan yang dapat dibagi-bagi yang dapat disusun-susun, dan alam ajsam juga itu alam tsahadati, artinya alam yang nyata. Itulah semua keberadaan yang dicapai panca indera yang lima. /11/ Pertama-tama alam ajsam yang dijadikan Allah SWT itu arasyi dan kursiy kemudian alam lalu laugh mahfuz lalu bulan tujuh lapis lalu tanah tujuh lapis. Arasy dan kursiy dan bulan tujuh lapis itu, itulah yang dinamakan wujud abaa'i, artinya, keadaan semua bapak ajsam, di bawah bulan tujuh lapis itu lalu tanah itu, itulah wujud Ulahâti, artinya keberadaan semua ibu ajsam di tanah itu, lalu ajsam beranakkan keadaan yang di atas dan keadaan yang di bawah itu tiga macam banyaknya: pertama-tama, ajsamul haiwanaati artinya tubuh semua hewan, lalu ajsamul haimâdati artinya wujud semua yang kental dan semua yang keras seperti emas, seperti tembaga, seperti besi, seperti timah. Lalu ajsam nabatati artinya wujud semua /12/ yang tumbuh seperti kayu, seperti rumput. Oleh karena itu sejak dikehendaki Allah SWT mengadakan yang tiga itu dipersyaratkanlah keberadaan di atas dan keadaan yang di bawah, menjadilah keberadaan yang tiga itu atas qudrat dan iradat Allah SWT, tidak semata-mata sebab serasinya yang dua keadaan itu; pertama-tama, jisim manusia yang 
diadakan Allah SWT di atas tanah ini ialah semua nenek kita Nabi Adam alaihi ssalam sehingga disebutlah dia abû al bataru artinya bapak semua badan manusia yang berkumpul pada kepala Adam itu anasir yang empat itu; air, angin, api, tanah. Yang Ketujuh pelengkap Martabat Tujuh itu martabat alam insan. Itulah yang dinamakan manusia. Alam insan itulah yang dinamakan juga martabat ajamiati, artinya pangkat yang mengumpulkan /13/ semua dalil yang menunjukkan keberadaan Allah SWT dan sifat jalal-Nya dan jamaaliNya, artinya sifat kebenaran-Nya dan sifat keelokan-Nya. Firman Allah SWT di dalam hadits qudsiy: mâ zhaharatu fî syai'in kazhuhûrî fil insâni, artinya tidak Aku nyata di dalam sesuatunya seperti kenyataan-Ku pada manusia. Manusia itulah tempat berkumpulnya dua jenis teladan; nyawa itu teladan haq, badan itu teladan khaliq; artinya: nyawa manusia itu teladan haq karena nyawa itu dengan sifat jalan dua puluh banyaknya seperti juga jumlah sifat Allah SWT yang dua puluhnya yang wajib itu, hanya saja hakikatnya berbeda sekali dengan sifatnya Allah SWT, artinya badan manusia itu teladan halqi karena tidaklah ada yang ada di alam besar ini /14/ kecuali ada juga pada badan manusia itu, seperti keberadaan tanah di alam besar itu teladan pada manusia adalah daging, batu di alam besar pada manusia adalah tulang, laut di alam besar pada manusia adalah ingus, air di alam besar pada manusia adalah ludah, kayu di alam besar pada manusia adalah rambut, api di alam besar pada manusia adalah suhu badan itu, angin di alam besar pada manusia adalah pernapasannya itu. Hingga akhirnya demikian itu. Itulah sehingga dinamakan alam saghir manusia itu artinya alam kecil. Kemudian hakikatnya manusia itulah alam kabir artinya alam besar, karena yang tidak ada yang ada di alam ini yang tidak ada teladannya pada manusia itu melainkan ada /15/ pada manusia tidak ada di alam besar ini seperti kalbi layatu rubbaniyah. Itulah yang tidak ada betul di alam yang lainnya. Selepasnya pada manusia, itulah yang disebut kalbi nurani, yang disebut ruh. Itulah juga yang ditanyakan Allah SWT di alam arwah. Firman Allah SWT alastu birabbikum qâlû balâ, artinya bukankah Aku Tuhan kamu? Berkata mereka itu, "Yah, Engkaulah Tuhan kami. Itulah keadaan yang mengetahui Tuhannya dengan jalan musyahidah dan muraqabah dan muqabalah dan mutawajjaha. Itulah yang difirmankan Allah SWT di dalam hadits qudsiy. Firman Allah SWT: mâ wasa'nî ardli wa lâ samâ'î wa lâkin wa sa'nî qalbi 'abdil mû'minittaqiyii, artinya, tidak leluasa Aku di bumi-Ku dan tidak leluasa Aku dilangit-Ku hanya leluasa Aku di kalbu hamba-Ku yang percaya /16/ yang takut, yang suci. Artinya leluasa Allah SWT itu di kalbi hamba-Nya yang percaya itu, karena kalbi itulah yang mengingat keadaan Allah SWT sehingga fanalah dia. Tidaklah mengetahui keadaan dirinya dan keadaan yang lainnya hanyalah keadaan Allah SWT. Itulah yang disabdakan Nabi shala llahu alaihi wassalam lî naqtin lâ'yas'anî fi hi ghairu rabbî, artinya ada satu waktu aku ini tidak leluasa aku di dalam waktu itu. Selepasnya Tuhanku tidak betul, artinya Allah SWT di kalbi itu telah masuk di situ sampai dan tinggal di situ, mustahil betul pada Allah SWT seperti itu". 
Maka yang diamanatkan Allah SWT pada manusia itu tujuh banyaknya. Itulah yang wajib pada manusia itu memperbaiki yang tujuh itu. Karena itulah yang paling besar amanat Allah SWT yang disimpan pada manusia itu. Amanat yang tujuh itu; Pertama-tama ,/17/ hidup. Itulah yang utama pada manusia. Wajib manusia itu memperbaiki hidupnya itu jangan dirusak hingga mematikan, kecuali dengan ridla Allah SWT. Kedua, pengetahuan. Wajib pada manusia itu pengetahuannya itu untuk mengetahui keadaan dirinya dan untuk mengetahui keadaan Tuhannya, karena siapa-siapa orang telah mengenal dirinya sebenarnya telah mengenal juga Tuhannya dan semua yang namanya yang wajib diketahuinya. Dipelihara betul pengetahuan pada dirinya itu, dan pengetahuan yang diwajibkan pada dirinya itu. Sabda Nabi shalallahu alaihi wasallam: ma'narafa nafsahu faqad 'arafa rabbahu, artinya siapa orang yang mengenal keadaan dirinya sebetulnya telah mengenal juga keadaan Tuhannya. Yang ketiga kuasa. Wajib bagi manusia kuasanya itu untuk melaksanakan semua ibadah wajib yang diwajibkan /18/ Allah SWT pada dirinya itu, baik ibadah dlahir maupun ibadah bathin. Dipelihara betul kekuasaannya itu dari berbuat maksiat baik maksiat dlahir maupun maksiat bathin. Yang keempat, kemauannya. Wajib bagi manusia itu segalayang namanya kemauan itu untuk kebaikan bagi dirinya di dunia dan di akhirat. Dipeliharanya betul kemauannya itu dari perbuatan yang merusakkan dirinya di dunia dan di akhirat. Kelima, pendengaran. Wajib manusia itu pendengarannya itu digunakan untuk mendengarkan perintah Allah SWT dan perintah Rasulullah dan larangan Allah SWT dan larangan Rasulullah.

Dipelihara betul pendengarannya itu dari mendengarkan kata yang tidak benar seperti makian atau tindakan hinaan atau fitnahan yang tidak benar. Keenam, penglihatan. Wajib bagi manusia itu penglihatannya itu untuk melihat hajatnya sendiri yang wajib pada agama seperti melihat pakaian sembahyangnya atau di tempat sembahyangnya. Jika tidak diketahuinya akan /19/ kebersihannya itu atau melihat hajatnya orang tuanya, yang layak untuk dilihat, atau untuk melihat jalan waktu berjalan jangan sampai lari orang sesamanya atau anak orang atau istri orang atau jangan sampai menginjak orang sesamanya. Dipelihara betul dari melihat yang haram seperti istri orang atau gundik orang atau anak perempuan orang, kecuali karena hajatnya seperti berjual beli, atau didatangkan dan bagaimanapun juga penglihatan yang wajib pada agama untuk melihat perempuan itu seperti yang sebenar-benarnya di dalam kitab fiqih itu. Ketujuh, berkata. Wajib manusia itu mengatakan segala kata yang diwajibkan Allah SWT, dia katakan seperti menanyakan sahnya 
itikadnya pada Allah SWT dan Rasulullah dan sahnya sembahyangnya dan puasanya dan zakatnya dan hajinya dan semua nama perbuatan seperti nikah dan segala /20/ yang sama dengan itu, wajib ditanyakan hukumnya satu persatu yang diperbuatnya itu atau seperti mengajari orang rumahnya atau anaknya atau hambanya yang bodoh-bodoh yang tidak mengetahui hukum agama. Dipelihara betul perkataannya itu dari pengucapan yang haram seperti memfitnah orang atau mengadukan, atau meremehkan atau mengangkat angkat dirinya atau mengadukan sesamanya atau berbohong dan sejenisnya itu. Itulah kesudahan amanat yang tujuh dari Allah SWT yang disimpan kepada manusia itu".

Teladan Martabat Tujuh dalam pangkat-pangkat semata-mata pada penghitungannya dan bukan pada hakikatnya. Perhatikan terjemahan kutipan teks berikut:

"Ketahuilah engkau teladan Martabat Tujuh pada pemerintahan Wolio itu, sudah pangkat-pangkat itulah. Teladan itu penghitungnnnya bukan hakikatnya. Teladan pada martabat ahadiah itu kaum Tanailandu; teladan martabat wahdah itu kaum Tapi-Tapi; teladan martabat/21/wahidiyah itu kaum kumbewaha; teladan martabat alam arwah itu sultan; teladan martabat alam mitsal itu sapati; teladan martabat alam ajsam itu kenepulu; teladan martabat alam insan itu kapitalao yang dua orangnya. Itulah urutan yang berasal dari Sultan Dayanu Ikhsanuddin Moßolina Pauna”.

Pada masa pemerintahan Mopogaana Pauna, terjadi perubahan pangkat, pangkat sultan dihilangkan, lalu digantikan dengan pangkat Lakina Sura Wolio. Perhatikan terjemahan kutipan teks berikut:

"Sampai pada zaman Sultan Mopogaana Pauna tidak ada lagi pangkat sultan, diadakanlah Lakina Sura Wolio menjadi pengganti dirinya. Dia mengganti dirinya alam barzah artinya alam pertemuan kaum yang tiga dan pertemuan pangkat-pangkat yang empat susunanya. Kesusahan kaum akan diadukan kepadanya, kesukaran pangkat-pangkat yang empat susunannya akan diadukan kepadanya. Jadi hari sekarang ini sapati itulah teladan alam arwah sampai akhir urutan-urutan yang tersebut/22/itu".

Sultan Mobolina Pauna berteladan pula pada sifat dua puluh, yang kemudian dibagi oleh dua pangkat, yaitu pangkat Sultan berjumlah dua belas dan pangkat Sapati berjumlah delapan. Perhatikan terjemahan kutipan teks berikut:

"Setelah Moßolina Pauna berteladan pada Martabat Tujuh itu berteladan pula pada sifat dua puluh. Sifat dua puluh itu wajib bagi siapa yang akil baligh disimpul mati di dalam hatinya. Pertama-tama, sifat yang wajib itu wujud; 
artinya ada. Kedua, qadim, artinya sedia. Ketiga, baqâ artinya kekal. Keempat, mukhalifatu llilhawâditsi artinya tidak sama dengan sesuatu yang baru. Kelima, qiyamuhu taala binafsihi artinya berdiri dengan sendirinya. Keenam, wahdaniyah artinya satu-satunya. Ketujuh, hayat artinya hidup. Kedelapan, ilmu artinya mengetahui. Kesembilan, qudrat artinya kuasa. Kesepuluh, iradat artinya kemauan. Kesebelas, samâ artinya mendengar. Kedua belas, basyar artinya melihat. Ketiga belas, kalam artinya yang berkata. Keempat belas, hiyat artinya hidup. Kelima belas, alim artinya yang maha mengetahui. Keenam belas, /23/ kadirun artinya yang kuasa. Ketujuh belas muridun artinya yang berkemauan. Kedelapan belas sami'un artinya yang mendengar. Kesembilan belas bashirun artinya yang melihat, Kedua puluh mutakalimun artinya yang berkata”.

Teladan Sifat Dua Puluh pada adat Wolio itu; sara yang dijaga sultan dan sapati; yang dijaga sultan itu ada dua belas; yang dijaga sapati itu delapan, sehingga genap dua puluh sifat. Selain berteladan pada "Martabat Tujuh" dan sifat "Dua Puluh" Sultan Mobolina Pauna berteladan pula pada al Quran yang tiga puluh juz dan i'tikad yang tujuh puluh dua kaum. Perhatikan terjemahan kutipan teks berikut:

"Teladan Quran yang tiga puluh juz itu menteri wolio itu, teladan i'tikad yang tujuh puluh dua kaumnya itu teladan syarak itu yang tujuh puluh dua teladannya adat Wolio. Jumlahnya yang tujuh puluh dua teladan pada adat Wolio, yang ditolak oleh adat Wolio itu. Itulah segala perilaku kasar, perkataan kasar. Itulah yang dinilai mentri siolimbona itu. Jika mereka itu melihat perbuatan yang baik, perkataan yang baik dan kelakuan yang baik. Berkatalah mereka itu; Susu bagamu yutuntu yolagi ßoli yumapiy ßamu /24/ Boli yamagari bulumu yukapeya duka yokayuncumarakana mangamamu manga yopuyamu yulempo duka yutuwupo duka yi tana si. Jika melihat menteri siolimbona itu yang berlawanan dengan yang tersebut itu, berkata pula mereka itu yusodompuye yulanyintoße ßoli yusoye yi polangomu ayinda ßeyuleyi ayinda ßeyutuwu yi tana yincina si. Oleh karena itu menurut cerita menteri siolimbona itu digantungkan tirai anyaman bambu di depan pintunya itu untuk mengamati perlakuan kaum yang tiga itu. Jika ada salah satu kelakuan dari yang tiga dilihatnya, itu wajar dapat diperingati, dipanggilnya ke rumahnya itu lalu diajari dengan baik-baik dan diperingati dengan baik-baik. Jika disegani siolimbona itu seperti bangsawan pembangkang, itulah yang mereka anjurkan sebab dia bisa menampakkan perkataan menteri siolimbona itu lebih dahulu digunakan pada dirinya perangai yang baik pada adat Wolio itu, sebab siolimbona itulah ulamanya pemerintah Wolio, mengamalkan pada dirinya adat Wolio itu. Jangan hanya berkata kata saja, sebab yang meninggikan martabat manusia itu pada Allah SWT /25/atau pada adat Wolio baik siolimbona atau jabatan yang lain atau yang tidak menjabat berawal dari merendahkan diri jika dia tidak tahu kerendahan dirinya atau tidak lagi merendahkan, kelak akan 
melakukan perbuatan buruk, perkataan buruk, perilaku buruk kelak akan mempengaruhi orang sesamanya kelak akan menghinakan orang sesamanya. Bersabda Nabi shalallahu alaihi wasallam man wadla'a nafsahu rafa'ahullâhu man rafa'a nafsahu wa dla'aahullâhu, artinya, siapa-siapa yang merendahkan dirinya akan ditinggikan Allah SWT, siapa-siapa yang meninggikan dirinya akan direndahkan Allah SWT. Jika telah tumbuh sifat kejahatan di dalam hati manusia itu kelak akan muncul di dalam hatinya manusia itu kelak lama akan muncul di dalam hati itu segala perangai buruk seperti, mengangkat dirinya, mengheran-herankan dirinya mempengaruhi sesamanya dari yang baik. Jika telah tetap di dalam hati perangai yang buruk itu kelak akan nyatalah pada ucapan akan nyata pada gerak gerik. Jika telah nyata pada perkataan atau pada tingkah laku perangai yang buruk. Itulah yang tidak disukai adat Wolio".

Menurut Muhammad Idrus terjadinya saling berdebat, saling melangkahi, saling tidak percaya serta berzina, adalah berpangkal pada kejahatan diri seseorang, tidaklah pantas kejahatan itu bila didiamkan dalam diri, akan tetapi harus menjadi tanggung jawab adat dan agama. Perhatikan terjemahan kutipan teks berikut:

"Menurut penafsiranku di jalan adat Wolio; adanya saling bertentangan bicara, saling melangkahi, saling tidak percaya, berzina di dalam negeri yang berpangkal pada kejahatan. Sangatlah tidak pantas keburukan itu berdiam pada diri seorang itu, kecuali tempat adanya keburukan itu pada adat Wolio. Itulah yang dikatakan para orang tua; tidak besar yang besar hanya sara, tidak tinggi yang tinggi hanya sara,tidak kuat yang kuat hanya sara, tidak berani yang berani hanya sara. Inilah kata orang tua, wujud kebesaran adat Wolio. Biarlah rusak harta asal jangan diri, biarlah rusak diri asal jangan negeri, biarlah rusak negeri asal jangan sara. Berkata ulama Muhaqiqi pada adat Wolio, biarlah rusak sara asal jangan agama”.

\section{Sultan}

Adat yang dijaga oleh sultan berjumlah dua belas. Perhatikan terjemahan kutipan teks berikut:

/26/" Yang besar rahasia yang dijaga sultan itu ialah; menilik lautan yang banyak, kemudian menutupkan kejahatan di luar. Kemudian sultan itulah yang menjadi orang tua di dalam menjadi orang tua /27/ di luar, kemudian adil. Hakikatnya keadilan sultan itu memperbaiki, baik yang sejalan dengan sara ataupun tidak. Itulah yang diteladani para orang tua dengan mengambil dalil faqâla limâ yurîdu artinya berbuat sekehendaknya. Adapun jenis-jenis sara yang dijaga sultan itu dua belas banyaknya; Pertama-tama, Sara Jawa. Sara Jawa itu empat banyaknya; Pertama-tama, paußia; Kedua, parmadani; Ketiga, gambi isoda; Keempat, sombah. Kedua, sara Pancana. Sara Pancana itu empat banyaknya; Pertama-tama, ßante; Kedua, kabutu; Ketiga, pomua; 
Keempat, kalonga. Yang ketiganya, Sara Wolio. Sara Wolio itu empat banyaknya; Pertama-tama, ßeloßaruga umana; Kedua, ßeloßarugaßawine; Ketiga, susua Wolio; Keempat, susua papara”.

Isi setiap adat berjumlah empat. Perhatikan terjemahan kutipan teks berikut:

Isinya Sara Jawa itu empat banyaknya; ßangka mapasa, rampe, ambara, ikane ogena. Isi Sara Pancana itu empat juga; popene, suruna /28/ karo, tali-tali, karambau. Adapun isi Sara Wolio itu empat; yisalâla, yikodosâka, yiatuâka, yimateaka.

\section{Sapati}

Rahasia adat yang dijaga Sapati diuraikan dalam terjemahan kutipan teks berikut:

"Yang besar rahasia sara yang dijaga sapati itu; asampaki, adolango, asalambi, abasarapu, memper hatikan gigi timbangan, kemudian menilik dua lautan, kemudian apa saja yang disepakati dikerasi. Itulah yang diteladani para orang tua dengan mengambil dalil innallâha lâyukhliful mî̀âdi, artinya sesungguhnya Allah SWT itu tidak merubah janji-Nya. Kemudian sudah sapati itulah tumpuan harapan sultan, harapan rakyat banyak".

Adapun adat Sapati berjumlah delapan. Perhatikan kutipan terjemahan teks berikut:

"Adapun jenis-jenis sara yang dijaga sapati itu delapan banyaknya; Pertama-tama, kamali tê daoa dan masjid. Kedua, ßaruga dan pasar. Ketiga, ßaluara têßadilina bedilnya. Keempat, batu tondo molele tê talangkera. Kelima, yolawa tê kajolina. Keenam, parigi tê patußana. Ketujuh, ßangka têßantena. Kedelapan, /29/ sulâna tombi tê pakaroana jaga”.

Isi kekuatan adat yang delapan dijelaskan dalam kutipan terjemahan teks berikut: pekamate”.

"Isi kekuatan, yang delapan itu; dosa, pasabu, pomurusi, papasi,

Adapun yang sampai kepada penjaga adat yang delapan itu, delapan juga jumlahnya. Perhatikan terjemahan kutipan teks berikut:

"Isi yang sampai pada penjaga yang delapan itu, delapan juga banyaknya; Pertama, tambena toba. Kedua, ßotu ßitara arata pusaka. Ketiga aba mopose yi taliku. Keempat molapasina anana. Kelima bangu tobata. Keenam, karoro pitu boka dua suku. Ketujuh, kasaße. Kedelapan, pupuna katepi”.

\section{Lakina Sora Wolio}


Adat Lakina Sora Wolio adalah meniru-niru segala bentuk adat yang dilaksanakan di istana kerajaan Buton. Perhatikan kutipan terjemahan teks berikut:

"Yang besar rahasia yang dijaga lakina Sara Wolio; meniru-niru, apoßatu tondo di kota besar ini apoßatu tondo juga dia, apotalangkeraka di kota besar ini apotalangkeraka juga dia”.

\section{Kenepulu}

Menurut teks Sarana Wolio adat yang dijaga kenepulu adalah mendengarkan bunyi tanah dan menjadi istri sah Sapati. Perhatikan terjemahan kutipan teks berikut:

"Yang besar sara yang dijaga kenepulu itu; mendengarkan bunyi tanah kemudian kenepulu itu adalah istri sah sapati. Yang disebut istri sah sapati kenepulu itu ialah dalam menghadapi sultan. Kemudian disebut istri sah sapati kenepulu itu menyepakati semua adat Wolio yang besar yang kecil, /30/ hanya bahagian-bahagiannya yang berpisah"

Kemudian adat yang dijaga Kenepulu berjumlah lima jenis. Perhatikan terjemahan kutipan teks berikut:

Kemudian jenis-jenis sara yang dijaga kenepulu itu lima banyaknya; Pertama, aratâ yindâ kawi. Kedua, yipêloana anana. Ketiga, yipêloa yipuana. Keempat, yanunua yitoputu. Kelima yoaratâ yiyo manako.

\section{Kapitalao}

Menurut teks Sarana Wolio rahasia adat Kapitalao adalah keberaniannya. Perhatikan terjemahan kutipan teks berikut:

"Yang besar rahasia adat yang dijaga kapitalao itu ialah keberanian itu; dialah keberanian sultan dan keberanian adat Wolio, kemudian pedangnya sultan dalam adat Wolio, kemudian harimaunya sultan dan harimaunya Sarana Wolio, /31/ kemudian kapitalao itulah hanya diperintah satu kali pada pemerintah Wolio".

\section{Mentri Besar}

Rahasia adat mentri besar adalah menjadi gundik sapati, sebilah pedang bagi kaum papara dan penyambung lidah Sapati. Perhatikan terjemahan kutipan teks berikut:

"Yang besar rahasia adat yang dijaga menteri besar itu ialah mengetahui dirinya. Menteri besar itu gundik-gundik sapati artinya disebut gundik itu yang menjaga, adat, yang dijaga sapati itu delapan dan semua isinya. Kemudian menteri besar itulah juga sebilah pedang pada papara Wolio. Kemudian sudah 
menteri besar itulah jenis-jenis penyambung lidah sapati, maka apa-apa adat yang dijaga menteri besar itu sembilan jenis banyaknya; Pertama, weti. Kedua, Bante. Ketiga, kabutu. Keempat, pomua. Kelima, kahoti mamata. Keenam, kahoti mamas. Ketujuh polongana kampua. Kedelapan, kalongana papara. Kesembilan aßa tê posanga”.

\section{Siolimbona}

Menurut teks Sarana Wolio rahasia adat bagi Siolimbona adalah sebagaimana dijelaskan dalam kutipan terjemahan teks berikut:

"Yang besar rahasia adat yang dijaga siolimbona itu adalah; mengetahui pangkat-pangkat serta mengetahui pulanga, kemudian /32/ menjaga kerusakan adat, kemudian mengamalkan jalannya adat Wolio, kemudian jika melihat yang melakukan matalapu jangan segan-segan mengingatkannya, kemudian mengajarinya semua peraturan adat Wolio baik peraturan besar maupun peraturan kecil".

\section{Pembahasan}

Pengaruh Islam yang akan dibahas dalam penelitian ini dibedakan atas beberapa unsur; 1) Tuhan, 2) Martabat Tujuh, 3) Sifat Dua Puluh, 4) Al Quran yang 30 Juz, 5) Unsur Itikad yang Tujuh Puluh Dua Kaum.

\section{Tuhan}

Setiap manusia yang beragama, khususnya yang beragama Islam, mempercayai dan meyakini bahwa Tuhan adalah zat yang Maha Tinggi, Maha Kuasa, Maha Tahu, Maha Pengasih, yang menciptakan langit dan bumi dan segala isinya. Dia bersifat kekal atau abadi untuk selama-lamanya, tunggal dan tidak ada sekutu bagi-Nya. Dia tidak beranak dan tidak pula diperanakkan.

Menurut Teks Sarana Wolio kedudukan Tuhan sering diserupakan dengan kedudukan adat Wolio. Hal ini sebagaimana terungkap dalam beberapa terjemahan kutipan teks berikut:

1) Tidak besar yang besar hanya pemerintah, tidak tinggi yang tinggi hanya pemerintah, tidak kuat yang kuat hanya pemerintah, tidak berani yang berani hanya pemerintah. Beginilah kata orang tua, hanya kebesaran adat Wolio.

2) Kemudian Adat Wolio itu dapat mengadakan yang tidak ada dan dapat meniadakan yang ada.

3) Kemudian adat Wolio itu dapat meninggikan yang rendah dan merendahkan yang tinggi.

4) Siapa-siapa yang mengecilkan orang lain, siapa-siapa yang tidak mengangkat 
orang lain, siapa-siapa yang tidak mengikuti adat Wolio, siapa-siapa yang tidak mematuhi adat wolio, siapa-siapa yang menyakiti hati orang lain akan direndahkan oleh Allah SWT akan direndahkan oleh adat Wolio.

5) Siapa-siapa yang menyayangi sesamanya, yang memelihara orang sesamanya, yang takut kepada orang sesamanya, yang menghormati orang sesamanya akan diangkat oleh Allah SWT diperbaiki, akan diangkat oleh adat Wolio, diperbaiki.

6) Kemudian yang disayangi oleh Allah SWT dan adat Wolio adalah fiil yang baik, perbuatan yang baik dan pakaian yang baik.

Sifat-sifat dan kekuasaan yang dimiliki adat Wolio sama dengan sifat-sifat Tuhan. Hal ini tidak berarti sultan Mobolina Pauna telah menyekutukan Tuhan dengan adat Wolio. Sultan Mobolina Pauna terbawa oleh perasaan keagamaan (pengaruh kesufiannya) yang mendalam dalam penyusunan adat Wolio. Adalah tidak dapat dicampur-baur antara pemahaman terhadap adat Wolio dan pemahaman terhadap Tuhan, maksudnya adat Wolio adalah menurut pemahaman adat dan Tuhan adalah pemahaman menurut ajaran keagamaan. Agama tetap menempati tempat yang paling tinggi daripada adat Wolio. Hal ini sebagaimana terungkap dalam terjemahan kutipan teks berikut:

"Hancur-hancurlah harta asal jangan hancur diri, hancur-hancurlah diri asal jangan hancur negeri, hancur-hancurlah negeri asal jangan hancur adat. Berkata ulama muhakiki pada adat Wolio, hancur-hancurlah adat asal jangan hancur agama”.

Tampaknya sultan Mobolina Pauna bukan hanya adat Wolio yang diserupakan dengan Tuhan tetapi juga kekuasaan sultan dan sapati. Hal ini sebagaimana terungkap dalam terjemahan kutipan teks berikut ini:

"Kemudian nama sultan itu Faqâla limâ yurîdu, artinya berbuat segala yang dikehendaki-Nya, kemudian nama sapati itu Innallaha lâyukhliful mî̀âdi artinya, sesungguhnya Allah SWT itu tidak merubah janji-Nya”.

Penyerupaan adat Wolio dengan Tuhan dapat meningkatkan ketaatan masyarakat pendukungnya terhadap adat Wolio. Mereka menganggap bahwa adat Wolio selain memiliki kekuatan mistik yang berasal dari luar Islam juga mengandung mistik Islam. Demikian pula penyerupaan sultan dengan Tuhan dan alam arwah dapat meningkatkan keyakinan bahwa sultan memiliki kekuasaan lahir dan bathin. Dengan kekuasaannya itu dia dipandang mampu melihat segala tingkah laku rakyatnya baik yang tampak maupun yang tersembunyi, mampu menguasai mereka baik fisik maupun mentalnya, baik jasmani maupun 
rohaninya. Dalam kaitan itu, menurut adat Wolio, sultan dapat berbuat sekehendaknya dan rakyat mesti dapat menerima segala perintahnya Faqâla limâ yurîdu, artinya berbuat sekehendaknya.

\section{Martabat Tujuh}

Di kalangan masyarakat Buton (Wolio), istilah Martabat Tujuh selain dikenal sebagai nama sebuah ajaran dalam dunia tasawuf, juga dikenal sebagai undang-undang kerajaan Buton. Sultan Mobolina Pauna diketahui sebagai sultan Buton pertama yang menyusun undang-undang Buton yang dipengaruhi ajaran tasawuf (Martabat Tujuh), karena itulah undang-undang ini disebut Undang-Undang Martabat Tujuh atau Martabat Tujuh saja. Selain itu, kiranya perlu ada batasan yang jelas mengenai perbedaan Martabat Tujuh sebagai ajaran tasawuf dan Martabat Tujuh sebagai Undang-Undang Kerajaan Buton.

Inti ajaran Martabat Tujuh sebagaimana diuraikan dalam teks sarana Wolio meliputi tujuh peringkat atau martabat yaitu:

Pertama, martabat ahadiyah yaitu zat Allah semata-mata. Para ahli sufi menyebutnya la-ta-ayun artinya tidak nyata kenyataannya sebab belum ditembus oleh akal. Yang diketahui semata-mata zat Allah, tidak muncul i'tibar sifat atau asma.

Kedua, martabat wahdah, yaitu sifat Allah. Para ahli sufi menyebutkan ta-ayun-awal, artinya kenyataan pertama sampainya akal untuk mengetahui zat Allah dan untuk memahami sifat Allah, karena sifat-sifat itulah yang menunjukkan zat, baik sifat sulbi maupun sifat maujud.

Ketiga, martabat wahidiyah, yaitu asma Allah. Para ahli sufi menyebutnya ta-ayun-tsani, artinya kenyataan kedua. Asma Allah disebut kenyataan kedua karena telah ada jalannya akal untuk mengetahui zat Allah. Asma itulah yang menunjukkan zat yang bersifat dengan segala sifat yang sesuai dengan zat-Nya.

Keempat, martabat alam arwah, yaitu keadaan semua nyawa, baik nyawa manusia maupun nyawa yang lainnya. Dijelaskan bahwa nyawa yang pertama yang dijadikan Allah SWT adalah nyawa Nabi Muhammad SAW, karenanya dia disebut abû al arwah artinya "bapak semua nyawa". Nyawa yang lainnya diciptakan dari kelebihan nyawa Nabi Muhammad SAW. Keadaan nyawa terlampau halus dan kecil sehingga tidak dapat dijangkau oleh panca indra manusia. Orang Arab menyebutnya ruh dan orang Buton menyebutnya lipa, artinya keluar masuk atau pergi pulang. Apabila Allah SWT menghendaki jasad itu agar mati, dikeluarkanlah nyawa itu dari jasad, akan tetapi nyawa tidak pernah mati. Jika di akhirat, nyawa itu dikembalikan lagi pada jasad, 
akan tetapi tidak seperti bentuk dan rupa jasad ketika masih di dunia, dia telah besar dan tinggi.

Kelima, martabat alam misal, yaitu permisalan semua keadaan. Keadaan alam misal sangat bermacam-macam rupanya, dan hanya Allah SWT jua yang mengetahui berapa jumlahnya. Misalnya; ada seperti nyawa tetapi bukan nyawa, seperti malaikat tetapi bukan malaikat, seperti jin tetapi bukan jin, seperti manusia tetapi bukan manusia, seperti batu tetapi bukan batu, seperti kayu tetapi bukan kayu dan seperti binatang tetapi bukan binatang. Keadaan alam misal seperti juga keadaan alam arwah yaitu masih sangat halus sehingga tidak dapat terjangkau oleh panca indra manusia.

Keenam, martabat alam ajsam, yaitu sama keadaan yang nyata seperti tanah, bulan, awan, batu, kayu dan air. Dia sudah dapat dibagi-bagi, dipilahpilah, serta dapat dijangkau oleh panca indra manusia. Alam ajsam disebut juga alam syahadah, artinya alam nyata. Pertama-tama yang dijadikan Allah SWT adalah arasyi dan kursiy, kemudian alam, kemudian laugh mahfuz, kemudian bulan tujuh lapis dan kemudian tanah tujuh lapis. Arasyi dan Kursiy serta bulan tujuh lapis itu disebut wujud aba'i artinya keadaan semua bapak ajsam. Di bawah bulan tujuh lapis kemudian tanah itu disebut wujud ulaha'ti, artinya keadaan semua ibu ajsam. Ibu ajsam beranakkan keadaan di atas dan di bawah meliputi tiga hal; pertama, ajsamul haiwana'ti artinya semua kejadian hewan, kedua, ajsamul haimâda'ti artinya kejadian yang kental dan yang keras seperti emas, tembaga, besi dan timah; dan yang ketiga, ajsamul naba'ta'ti, artinya kejadian semua yang tumbuh, seperti kayu dan rumput. Semua keadaan yang tiga itu diciptakan tidak semata-mata karena atas serasinya dua keadaan di atas dan keadaan di bawah akan tetapi atas qudrat dan iradat Allah SWT. Jism pertama yang diciptakan Allah SWT di atas tanah adalah jism manusia yaitu nenek kita Nabi Adam AS, karenanya ia disebut abuwal bataru artinya bapak semua jasad. Semua jasad manusia berkumpul pada kepala Adam itu yang meliputi anasir; air, angin, api, dan tanah.

Ketujuh, martabat alam insan, yaitu manusia. Martabat manusia disebut juga martabat ajamiati artinya pangkat yang mengumpulkan semua dalil yang menunjukkan keadaan Allah SWT baik sifat Jalal-Nya maupun Jamâli-Nya, artinya sifat kebenaran dan keelokan-Nya. Manusia merupakan tempat bekumpulnya dua jenis teladan; yaitu nyawa merupakan teladan haq dan badan merupakan teladan khaliq. Nyawa manusia disebut teladan haq karena nyawa itu adalah jalan sifat dua puluh seperti juga sifat dua puluh pada Allah SWT, hanya saja hakikatnya yang berbeda dengan sifat Allah SWT, artinya badan manusia 
merupakan teladan halqi karena semua yang ada di alam besar ada juga pada badan manusia. Misalnya, tanah di alam besar, pada manusia adalah daging, batu pada alam besar, pada manusia adalah tulang, laut di alam besar, pada manusia adalah ingus, air pada alam besar, pada manusia adalah ludah, kayu di alam besar pada manusia adalah rambut, api di alam besar pada manusia adalah suhu badan, angin pada alam besar pada manusia adalah pernapasan, dan seterusnya seperti itu. Alam pada manusia disebut alam saghir artinya alam kecil yang pada hakikatnya manusia itu adalah alam kabir artinya alam besar karena tidak ada yang ada di alam besar ini yang tidak ada teladannya pada manusia. Akan tetapi tidak semua yang ada pada manusia ada teladannya di alam besar, yaitu kalbu nurani yang disebut ruh. Itulah yang ditanyakan Allah SWT ketika berada di alam arwah. Firman Allah SWT yang artinya "Tidak leluasa Aku di bumi-Ku dan tidak leluasa Aku di langit-Ku, hanya leluasa Aku di kalbu hamba-Ku yang percaya, yang takut dan yang suci”. Yang dimaksud dengan leluasa Allah SWT di kalbu hamba-Nya yang percaya itu artinya bahwa kalbu itu yang mengingat keadaan Allah SWT sehingga fanalah dia. Itulah yang disabdakan oleh Nabi Muhammad SAW yang artinya "ada satu waktu aku ini tidak leluasa aku di dalam waktu itu".

Tujuh peringkat wujud dalam martabat tujuh tersebut, kemudian digunakan oleh sultan Mobolina Pauna sebagai tamsil atau teladan dalam penetapan jumlah pangkat atau jabatan dalam struktur adat Wolio; pangkat pertama, kaum Tanailandu disamakan dengan martabat ahadiyah, pangkat kedua, kaum Tapi-tapi disamakan dengan martabat wahdah, pangkat ketiga, kaum Kumbewaha disamakan dengan martabat wahidiyah, pangkat keempat, sultan disamakan dengan martabat alam arwah, pangkat kelima, sapati disamakan dengan martabat alam mitsal, pangkat keenam, kenepulu disamakan dengan martabat alam ajsam, dan pangkat ketujuh, kapitalao yang dua orang disamakan dengan martabat alam insan.

Tiga pangkat pertama (kaum Tanailandu, Tapi-tapi, dan Kumbewaha) dalam istilah adat dikenal dengan nama $k a m \beta$ oru- $\beta$ oru tulupalena, yaitu tiga pangkat batiniah yang bersifat kekal yang menjadi cikal-bakal atau asal-usul kaum bangsawan yang kelak akan menduduki empat pangkat berikutnya yang bersifat lahiriyah (sultan, sapati, kenepulu, dan kapitalao). Diketahui bahwa undang-undang ini pertama kali disusun oleh tiga orang tokoh masing-masing; Mobolina Pauna, pejabat Sultan dari golongan bangsawan kaum Tanailandu, La Singga pejabat sapati berasal dari golongan kaumu Tapi-Tapi, dan La Bula pejabat kenepulu berasal dari golongan bangsawan kaumu Kumbewaha. Adapun pejabat 
kapitalao pada masa itu tidak disebut namanya, akan tetapi ia juga berasal dari salah satu dari ketiga golongan bangsawan tersebut. Pada prinsipnya antara golongan bangsawan yang satu dengan golongan bangsawan yang lainnya dari ketiga golongan itu masih tergolong hubungan keluarga dekat.

Kesamaan atau keserupaan antara adat Wolio dengan Martabat Tujuh sesungguhnya lebih condong pada jumlah perhitungan pangkatnya daripada makna yang dikandung oleh setiap pangkat, terungkap dalam terjemahan kutipan teks; "Ketahuilah engkau teladan martabat tujuh pada adat Wolio itu, sudah pangkat-pangkatnya itu teladannya. Penghitungannya bukan hakikatnya”.

Dengan demikian haruslah dibedakan antara pemahaman terhadap makna yang dikandung oleh setiap pangkat dalam adat Wolio dan pemahaman terhadap makna yang dikandung oleh setiap pangkat atau martabat dalam Martabat Tujuh, dalam hal ini pangkat-pangkat dalam pemerintah harus dijelaskan menurut pemahaman adat dan Martabat Tujuh dan menurut pemahaman tasawuf (Islam). Pada masa itu (masa pemerintahan Sultan Mobolina pauna (1597-1633), alam pemikiran masyarakat Buton di kalangan istana kerajaan khususnya kalangan bangsawan dan petinggi kerajaan sangat diwarnai oleh cara berpikir kesufian. Sultan Mobolina Pauana sendiri memperoleh ajaran tasawuf Martabat Tujuh dan Sifat Dua Puluh dari salah seorang gurunya bernama Syarif Muhammad. Menurut beliau, masuknya pengaruh tasawuf (Martabat Tujuh dan Sifat Dua Puluh), itulah yang menjadikan adat Wolio menjadi berkah.

Sangatlah mungkin Sultan Mobolina Pauna yang latar belakangnya sebagai seorang sufi jika dalam menerapkan kebijakan politiknya dalam pemerintahan juga dipengaruhi alam pemikiran kesufiannya. Adanya pembatasan tujuh pangkat dalam pemerintahan Wolio yang diserupakan dengan jumlah pangkat dalam Martabat Tujuh serta pembatasan tiga asal golongan bangsawan kaumu (Tanailandu, Tapi-Tapi, dan Kumbewaha) yang kemudian diserupakan dengan tiga martabat (ahadiah, wahdah, dan wahidiyah) dalam Martabat Tujuh yang kelak akan menduduki empat jabatan penting (sultan, sapati, kenepulu, dan kapitalao) dalam pemerintahan Wolio merupakan contoh kongkret akan hal itu. Sejak masa pemerintahan Sultan La Elangi telah ditetapkan bahwa jabatan sultan tidak lagi berasal dari putra mahkota, akan tetapi melalui suatu proses pemilihan oleh dewan ahli adat yang disebut Siolimbona. Meskipun melalui suatu proses pemilihan, akan tetapi dengan adanya kebijakan politik yang membatasi ruang lingkup bangsawan kaumu yang kelak mengikuti pencalonan jabatan sultan, maka kelak sultan terpilih pun masih tergolong lingkungan keluarga juga. 
Pada masa pemerintahan sultan Mopogaana Pauna (1645-1656), pangkatpangkat adat Wolio yang ditetapkan Sultan Mobolina Pauna mengalami perubahan. Sultan Mopogaana Pauna mengadakan jabatan Lakina Sora Wolio sebagai salah satu jabatan strategis dalam pemerintahan Wolio. Jabatan ini dimasukkan dalam struktur kepangkatan adat Wolio yang tujuh. Dengan demikian, pangkat sultan tidak lagi masuk dalam struktur kepangkatan yang tujuh. Sultan Mopogaana Pauna memposisikan pangkat sultan sebagai penghubung antara pangkat yang tiga (Tanailandu, Tapi-tapi, dan Kumbewaha) dengan pangkat yang empat (sapati, kenepulu, Lakina Sora Wolio dan kapitalao). Pangkat sultan tidak lagi diserupakan dengan martabat ahadiah akan tetapi diserupakan dengan alam barzah.

Sultan Mopogaana Pauna tetap mempertahankan jumlah pangkat yang ditetapkan Sultan Mobolina Pauna. Perbedaannya terletak pada isi pangkat keempat sampai dengan pangkat keenam (Sultan, Sapati dan Kenepulu) yang diserupakan dengan martabat alam arwah, alam misal dan alam ajsam, sedangkan menurut Sultan Saparigau terdiri atas pangkat (sapati, kenepulu dan lakina Sora Wolio) yang juga diserupakan dengan martabat alam arwah, alam misal dan alam ajsam. Pangkat sultan menurut adat Wolio diserupakan maknanya dengan martabat alam arwah, akan tetapi menurut Sultan Mopogaana Pauna, yang diserupakan dengan pangkat alam arwah adalah sapati, pangkat sultan diserupakan dengan alam barzah. Demikian pula dengan pangkat sapati dan kenepulu menurut adat Wolio Sultan Mobolina Pauna, diserupakan dengan martabat alam misal dan alam ajsam, dan menurut Sultan Mopogaana Pauna, martabat alam misal dan alam ajsam diserupakan dengan pangkat kenepulu dan pangkat Lakina Sora Wolio.

Menurut sultan Mobolina Pauna, jabatan sultan merupakan jabatan yang paling mulia di dalam pemerintahan Wolio, selain asal usulnya jelas yaitu dari golongan bangsawan kamboru-boru talupalena (kaum Tanailandu, Tapi-Tapi dan Kumbewaha), ia juga merupakan hasil pilihan rakyat melalui dewan ahli adat yang disebut mentri Siolimbona. Mereka ini berasal dari golongan walaka. Dalam pada itu, sultan diposisikan sebagai anak oleh mentri Siolimbona, dan mentri Siolimbona diposisikan sebagai bapak oleh sultan, dalam arti bahwa sultan dianggap anak mentri Siolimbona karena merekalah yang memilih dan mengangkatnya sebagai sultan. Dalam adat Wolio, sultan dianggap suci dari adat, dianggap sebagai bayi yang berada di atas pangkuan ibunya, yang pekerjaannya hanya menangis dan tertawa.

Fungsi Martabat Tujuh dalam pembentukan pangkat-pangkat adat 
Wolio adalah melegitimasi kedudukan para pejabat penting dalam adat Wolio (sultan, sapati, kenepulu dan kapitalao) beserta asal-usulnya (kaum Tanailandu, kaum Tapi-Tapi, dan kaum Kumbewaha) sehingga meningkatkan kharismatik, kewibawaan dan kewenangan mereka sebagai penguasa dalam pemerintahan Wolio. Kebijakan politik Sultan Mobolina Pauna menetapkan tujuh pangkat dalam adat Wolio ini pada prinsipnya merugikan hak-hak bangswan lain di luar bangsawan yang tiga (kaumu Tanailanu, kaum Tapi-Tapi, dan kaumu Kumbewaha) untuk mendapatkan kesempatan menduduki empat jabatan penting (sultan, sapati, kenepulu dan kapitalao) dalam adat Wolio. Selain itu, ia melegitimasinya baik secara adat maupun secara agama (tasawuf Islam).

Hubungan keserupaan makna antara tujuh pangkat dalam adat Wolio Sultan Mobolina Pauna dan ajaran Martabat Tujuh terdapat pada proses penciptaannya. Proses-proses penciptaan alam semesta (dunia makrokosmos) oleh Allah SWT melalui tujuh peringkat wujud atau martabat (ahadiah, wahdah, wahidiyah, alam arwah, alam misal, alam ajsam dan alam insan) diserupakan dengan proses penciptaan pangkat-pangkat dalam adat Wolio (dunia mikrokosmos) oleh Sultan Mobolina Pauna yang juga melalui tujuh peringkat wujud atau pangkat (kaumu Tanailandu, kaumu Tapi-Tapi, dan kaumu Kumbewaha, sultan, sapati, kenepulu dan kapitalao) atau oleh Sultan Mopogaana Pauna yang juga melalui tujuh pangkat (kaumu Tanailandu, kaumu Tapi-Tapi, dan kaumu Kumbewaha, sapati, kenepulu, Lakina Sora Wolio, dan kapitalao). Dengan demikian terkesan bahwa pangkat-pangkat adat Wolio dianggap sama dengan Martabat Tujuh. Menurut pandangan Sultan Mobolina Pauna yang juga seorang sufi, hal ini bukan berarti telah terjadi penukaran agama (ajaran Martabat Tujuh) dengan Sarana Wolio (pangkat-pangkat adat Wolio) sehingga keyakinan terhadap agama dapat diganti dengan keyakinan terhadap Sarana Wolio. Sultan Mobolina Pauna sangat dipengaruhi oleh perasaan keagamaan yang mendalam, dan bukan keyakinannya terhadap adat Wolio. Pada masa itu (abad ke-17) penulisan karya undang-undang di Nusantara sangat mengemuka yang dimulai dari kesultanan Aceh (Hooker, 1984 : 7). Pada masa itu pula ajaran tasawuf heterodoks berkembang luas. Ia berazaskan doktrin tujuh tahap kewujudan yang dikenali sebagai wujudiyah.

\section{Sifat Tuhan Yang Dua Puluh}

Pada hakikatnya ajaran tasawuf menganai sifat Tuhan yang dua puluh tidak dapat dipisahkan dengan ajaran tasawuf Martabat Tujuh. Sebagaimana 
telah dikemukakan terdahulu bahwa martabat pertama dalam Martabat Tujuh yang disebut martabat ahadiyah yang semata-mata hanya mengenal zat Allah, maka pada martabat yang kedua yaitu martabat wahdah telah mengenal sifat-sifat Allah. Para ahli sufi menyebutkan ta-ayun-awal yang artinya kenyataan pertama sampainya akal mengenal zat Allah untuk memahami sifat Allah. Sifat Allah itulah yang menunjukkan zat Allah, baik sifat sulbi maupun sifat maujud. Hal ini sebagaiman firman Tuhan, zâtullahi qadîmun, artinya zat Allah itu sedia adanya atau zâtullahi baqâ'un artinya zat Allah itu kekal, atau zâtullahi mukhâlifatu lilhawâditsi, artinya Allah SWT itu tidak sama dengan segala sesuatu yang baru, zâtuhu yatusifu bilhiya'ti artinya zat Allah itu bersifat hidup atau seumpama dengan itu.

Dalam hubungannya dengan adat Wolio, jumlah sifat Tuhan yang dua puluh tersebut digunakan oleh Sultan Mobolina Pauna untuk menetapkan jumlah kelengkapan adat bagi sultan dan sapati yang juga berjumlah dua puluh. Hal ini sebagaimana terungkap dalam terjemahan kutipan teks Sarana Wolio di bawah ini:

Teladan Sifat Dua Puluh pada adat Wolio itu; adat yang dijaga sultan dan sapati; yang dijaga sultan itu ada dua belas; yang dijaga/sapati itu delapan; dua puluh semua.

Adat yang delapan dilengkapi dengan isi kekerasan yang terdiri atas lima hal pokok; dosa, pasabu, pomurusi, papasi dan pekamate. Adapun yang sampai kepada penjaga kelengkapan adat itu juga meliputi delapan bagian yaitu;

Pertama, tambena toba, kedua, kasabe, ketiga, bangu te tobata, keempat, karoro tujuh ßoka dua suku, kelima, kaß atuana rambanua dan suludaduna kambilo tujuh $\beta$ oka dua suku, keenam, $\beta$ otu $\beta$ itara arata pusaka, ketujuh, a $\beta$ a moposana yi taliku, kedelapan, pupuna katepi.

\section{Al Quran Yang Tiga Puluh Juz}

Al Quran adalah kalam Allah SWT yang merupakan mukjizat yang diturunkan (diwahyukan) kepada Nabi Muhammad SAWdan membacanya adalah ibadah, al Quran merupakan sumber dari segala sumber hukum dan kebenarannya yang bersifat mutlak (Adlani, 2001: xi). Al Quran tersusun dalam 30 juz. Dalam hubungannya dengan adat Wolio, jumlah juz al Quran yang 30 juz ini digunakan oleh Sultan La Elangi untuk menentukan jumlah mentri dalam adat Wolio yaitu berjumlah 30 orang. Ketiga puluh orang dimaksud berasal dari golongan walaka. 


\section{Itikad Yang Tujuh Puluh Dua Kaum}

Pada masa pemerintahan Sultan Mobolina Pauna tampaknya telah masuk pula ajaran tentang aqidah salaf ahlus Sunnah wal-jamaah, yang antara lain ajarannya adalah menjelaskan ikhwal perpecahan dalam dunia Islam menjadi 72 kaum. Perpecahan itu terutama disebabkan oleh pemahaman mereka yang sesat terhadap agama Islam. Hal ini sebagaimana dikemukakan:

"asal kesesatan setiap firqah yang ada di dalam Islam disebabkan pemahaman mereka yang sangat buruk terhadap agama Islam. Mereka telah menerjemahkan dan menafsirkan Islam sesuai dengan hawa nafsu dan akal-akal mereka yang rendah" (Abdul Hakim, 2005: 10).

Hubungannya dengan adat Wolio, perpecahan dalam dunia Islam yang berjumlah 72 kaum itu, digunakan oleh Sultan La Elangi untuk menetapkan jumlah itikad yang ditolak oleh adat Wolio, yang juga berjumlah 72 itikad. Tidak ada penjelasan secara detail dalam teks kaum-kaum apa saja yang mengalami perpecahan itu. Demikian pula tidak ada penjelasan secara detail itikad apa saja yang ditolak oleh adat Wolio itu. Yang disebutkan hanya mengenai perilaku jahat.

Menurut adat Wolio, pejabat yang berwenang mengawasi perilaku kaum bangsawan dalam adat Wolio adalah dewan ahli adat yang tergabung ke dalam mentri Siolimbona. Mereka ini berasal dari golongan walaka. Kalangan bangsawan yang menjadi objek utama pengawasan mereka adalah bangsawan yang tergolong ke dalam kamboru-boru talupalena (Kaumu Tanailandu, Kaumu Tapi-tapi, Kaumu Kumbewaha). Mereka ini kelak akan menduduki jabatan penting dalam adat Wolio (sultan, sapati, kenepulu dan kapitalao). Apabila mereka memperlihatkan yang baik, mentri Siolimbona tidak ragu-ragu mengeluarkan kata-kata seperti berikut ini;

"Susu bagamu yutuntu yolagi ßoli yumapiy ßâmu ßoli yamagari bulumu yukapeya duka yokayuncumarakana mangâmamu manga yopuyamu / yulempo duka yutuwupo duka yi tana sî".

Akan tetapi apabila mereka memperlihtkan perilaku yang tidak baik, mentri Siolimbona pun tidak ragu-ragu mengeluarkan kata-kata kutukan kepada para bangsawan dimaksud yaitu; Yusodompuye yulanyintoße ßoli yusoye yi polangomu ayinda ßeyuleyi / ayinda ßeyutuwu yi tana yincina sî.

Oleh karena itulah, di depan pintu rumah mentri Siolimbona selalu tergantung tirai anyaman bambu yang bercelah, dimaksudkan untuk mengintip setiap saat perilaku para bangsawan dari kamboru-boru talupalena yang melalui atau lewat di depan rumah mereka. Kata-kata kutukan seperti tersebut di atas hanya dapat dikeluarkan oleh mentri Siolimbona apabila para bangsawan 
dimaksud tidak lagi mengindahkan segala nasihat ataupun peringatan mentri Siolimbona itu.

\section{Simpulan}

Berdasarkan hasil pembahasan dapat disimpulkan bahan penyusunan Undang-Undang Buton (Wolio) dengan mengambil tamsil unsur-unsur tasawuf yaitu adat Buton ditamsilkan dengan Tuhan, jumlah pangkat-pangkat ditamsilkan dengan tujuh peringkat dalam Martabat Tujuh, jumlah adat sultan dan sapati ditamsilkan dengan sifat Dua Puluh, jumlah menteri ditamsilkan dengan tiga puluh juz al Quran, jumlah itikad yang ditolak oleh adat ditamsilkan dengan itikad yang tujuh puluh dua kaum dimaksudkan selain untuk melegitimasi adat Buton menjadi adat Islam, juga untuk melegitimasi kedudukan para pejabat penting dalam adat Wolio (Sultan, Sapati, Kenepulu, Lakina Sora Wolio dan Kapitalao). Namun demikian, dari segi pemahaman adat harus dijelaskan secara adat dan pemahaman agama harus dijelaskan secara agama. Pada masa itu, Sulatan Dayanu Ikhsanuddin dan para pejabat istana sangat diwarnai oleh alam pikiran Kesufian.

\section{Daftar Pustaka}

Abdul Hakim. 2005. Kesahihan hadits Iftiraaqul Ummah Firqah-Firqah Sesat Di dalam Islam. Jakarta: Pustaka Imam Muslim

Adlani. Nazri dkk. 2002. Al Quran Terjemah Indonesia. Jakarta: Sari Agung.

Baried, Siti Baroroh, dkk. 1994. Pengantar Filologi. Yogyakarta: BPPF Seksi Filologi Universitas Gajah Mada.

Braginsky, V.I. 1993. Tasawuf dan Sastra Melayu Kajian dan Teks-Teks. Jakarta: Pusat Pembinaan dan Pengembangan Bahasa Depdikbud RI dan Universitas Leiden, Belanda.

Braginsky, V.I. 1998. Yang Indah Berfaedah dan Kanal Sejarah Sastra Melayu dalam Abad 7-19. Jakarta: INIS.

Couvreur, J. 2001. Sejarah dan Kebudayaan Kerajaan Muna. Kupang: Artha Wacana Press.

Hadi, Abdul. 2001. Tasawuf yang Tertindas: Kajian Hermeneutik Terhadap KaryaKarya Hamzah Fansuri. Jakarta: Paramadina. 
Hooker, M.B. 1984. Undang-Undang Islam Di Asia Tenggara. Terjemahan oleh Rohani Abdul Rahim, dkk. 1992. Kuala Lumpur: Dewan Bahasa dan Pustaka.

La Niampe. 2009. Undang-Undang Buton Versi Muhammad Idrus Kaimuddin. Kendari FKIP Unhalu

La Niampe. 2010. Unsur-Unsur Tasawuf Dalam Undang-Undang Buton. AlFikr, Jurnal pemikiran Islam. Volume 15 No.3

Mu'jizah. 2005. Martabat Tujuh: Edisi Teks dan Pemahaman Tanda suatu Simbol. Jakarta: Djambatan

Naguib Al-Attas, Shed M. 1972. Islam dalam Sejarah Kebudayaan Melayu. Kuala Lumpur: Universitas Kebangsaan Malaysia.

Robson, S.O. 1994. Prinsip-Prinsip Filologi Indonesia (Terjemahan). Jakarta: RUL.

Sani Usman, Abdullah. 2005. Nilai Sastra Ketatanegaraan dan Undang-Undang dalam Kanun Syarak Kerajaan Aceh dan Bustanus Salatin. Bangi: Universiti Kebangsaan Malaysia

Schoorl, Pim. 2003. Masyarakat, Sejarah dan Kebudayaan Buton. Jakarta: Djambatan.

Sutrisno, Sulastin. 1983. Hikayat Hang Tuah: Analisa Struktur dan Fungsi. Yogyakarta: Gajah Mada University Press.

Yunus, Abdul Rahim. 1995. Posisi Tasawuf dalam Sistem Kekuasaan di Kesultanan Buton pada Abad ke-19. Jakarta: INIS.

el Harakah Vol.14 No.2 Tahun 2012 